\title{
A influência dos recursos naturais e dos aspectos físico-geográficos na configuração territorial da América do Sul
}

\author{
The influence of natural resources and features of physical geography to South \\ America's territorial arrangement
}

\author{
Luis Antonio Bittar Venturi \\ Professor Livre docente, Departamento de Geografia \\ Universidade de São Paulo. São Paulo, Brasil
}

\begin{abstract}
Resumo
A configuração territorial da América do Sul - um grande país rodeado de países de países de dimensões menores - é explicada por fatores históricos, como pelo fato de o Brasil ter se tornado um vice-reino. A presença da família real na colônia teria favorecido sua integridade. Normalmente, os fatores geográficos são negligenciados nessa explicação, sobretudo aqueles relacionados aos recursos naturais e os aspectos físicos da paisagem. Aqui, pretendemos preencher esta lacuna temática trazendo os fatores geográficos para a análise explicativa do território sul-americano. Metodologicamente, a análise comparativa entre a América Espanhola e a Portuguesa orientou-se por duas variáveis: a natureza dos recursos naturais explorados e as características físicas do território. Pautamo-nos também por quatro premissas: $\left.1^{a}\right)$ A movimentação pelo território como condição para assegurar seu domínio; $\left.2^{a}\right)$ Recursos naturais de biomassa implicam em maior movimentação; $3^{\underline{a}}$ ) Atividades mineradoras, por serem locais, implicam em maior urbanização e, consequentemente, criam ambientes mais favoráveis aos movimentos revolucionários; $4^{a}$ ) Relevos mais planos, hidrografia caudalosa e climas variados sem extremos favorecem o desenvolvimento de diversas atividades agropecuárias e, consequentemente, a ocupação do território. Concluímos que a combinação destas variáveis e premissas auxiliam na explicação da configuração do território sul-americano.
\end{abstract}

Palavras-chave: recursos naturais, aspectos geográficos, aspectos históricos, território, América do Sul

\begin{abstract}
South America's territorial arrangement - a big country surrounded by smaller ones - is clarified by historical factors, as due to the fact that Brazil has become a viceroyalty. The Royal family's presence in the colony would have favoured its integrity. Normally, the geographic factors are neglected in this explanation, especially those related to natural resources as physical aspects of the landscape. Here we intend to fill this thematic gap applying the geographic facts to the explanatory analysis of the South-American territory. Methodologically, the comparative analysis between The Spanish America and the Portuguese was conducted by two variables: the nature of the explored natural resources and the physical features of the territory. Our main idea is founded on four premises: 1 -Moving through the territory as a condition to assure domination. 2 - Biomass natural resources lead to farther moving. 3 - Considering that mining activities are local they beget urban development and consequently became a fertile ground for revolutionary movements. 4 - Flat relief, large rivers and mild temperatures encourage the development of farming activities and therefore the occupation of territory. We conclude that the combination of these variables and premises may throw new light on comprehending South America's territorial arrangement.
\end{abstract}




\section{Introdução}

O contexto territorial do continente sul americano desperta a atenção para o fato de a América Portuguesa ter originado um país de grandes dimensões, enquanto a América Espanhola desdobrou-se em diversos estados-nação. Este fato é explicado pelos historiadores por diversos argumentos, entre eles, a vinda da coroa portuguesa ao Brasil transformando a colônia em vice-reino. A presença da família imperial e seus deslocamentos internos teriam favorecido a unicidade territorial do que viria a ser o Brasil moderno. As viagens de D. Pedro II, tanto internamente como ao exterior buscando promover o Brasil e atrair colonos também teriam contribuído para o povoamento e, consequentemente, para a manutenção territorial1.

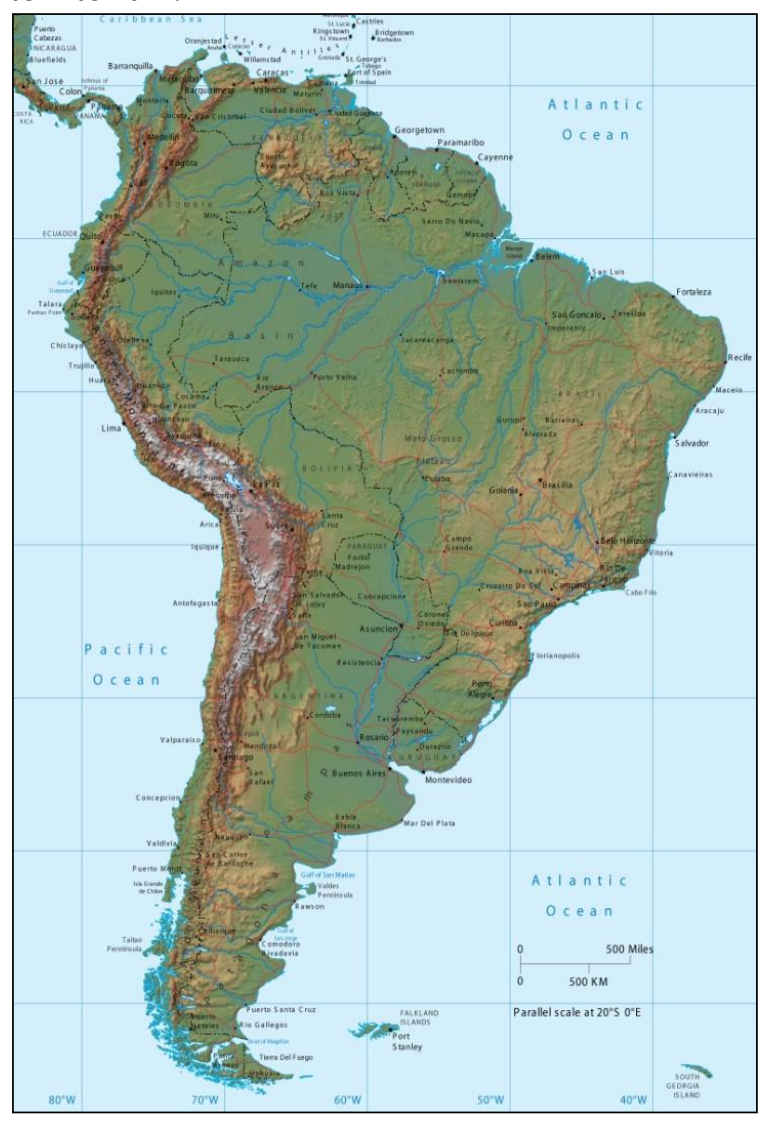

Figura 1 - Configuração territorial da América do Sul com diversos países de dimensões menores, em contraste com o Brasil. Fonte: Atlas Mundial DK.

Do lado espanhol, os historiadores ressaltam a importância dos movimentos revolucionários de libertação das colônias da coroa espanhola. Aqui, as premissas históricas estão preservadas.

Mas quais outros fatores poderiam ter contribuído para esta peculiar configuração territorial da América do Sul? Para responder a esta questão motriz, propomos complementar os argumentos históricos com argumentos geográficos relacionados aos recursos naturais e às características físicogeográficas do território das ex-colônias.

\section{Objetivo}

Nesse contexto, o objetivo deste estudo é evidenciar como a natureza dos recursos naturais explorados, assim como as características físicas do território foram fundamentais, tanto para a manutenção da integridade territorial da América Portuguesa, quanto para a fragmentação da América Espanhola.

\section{Método}

Metodologicamente, este estudo foi conduzido por uma análise comparativa da América Espanhola e Portuguesa pautada em duas variáveis e quatro premissas

Variáveis analíticas:

$1^{\text {a }}$ ) A natureza dos recursos naturais explorados (Biomassa X Minerais)

$\left.2^{\mathrm{a}}\right)$ As principais características físicoterritoriais (Relevo, Hidrografia, Clima)

\section{Premissas:}

$1^{\mathfrak{a})}$ A movimentação pelo território era condição para assegurar seu domínio;

$\left.2^{\mathrm{a}}\right)$ Recursos naturais de biomassa implicam em maior movimentação pelo território;

$\left.3^{a}\right)$ Atividades mineradoras, por serem mais - pontuais, implicam em maior urbanização e, consequentemente, criam ambientes mais favoráveis aos movimentos revolucionários;

$\left.4^{\mathrm{a}}\right)$ Relevos mais suaves, hidrografia caudalosa e climas variados sem extremos favorecem o desenvolvimento de diversas atividades agropecuárias e, consequentemente, a ocupação do território. 
O cruzamento dos dados dessas duas variáveis produziu, então, uma compreensão acerca da maior ou menor movimentação da população e, consequentemente, na maior ou menor manutenção da integridade territorial. Estes argumentos, acrescidos às premissas históricas já mencionadas, explicariam a questão motriz: por que há, no continente sulamericano, um grande país rodeado de países menores.

\section{Desenvolvimento}

Primeira variável: recursos naturais explorados nas colônias

América Portuguesa $\rightarrow$ predomínio das biomassas

A história do Brasil colônia está ligada à exploração, seja por extrativismo ou por cultivo, de recursos naturais essencialmente relacionados à biomassa. À exceção do ciclo do ouro ${ }^{1}$, todos os outros ciclos econômicos envolveram biomassas. Inicialmente, o primeiro recurso natural explorado, e que deu nome ao país, foi o pau-brasil. Como esta espécie espalhava-se por toda a mata Atlântica, do nordeste a sudeste, sua exploração exigiu o deslocamento pelas áreas costeiras, especialmente da região nordeste, pois o pau-brasil de Pernambuco era considerado de melhor qualidade. Embora inicialmente não tenha havido fixação dos portugueses na colônia, já que a extração era realizada pelos indígenas, em algumas áreas da costa construíram-se alguma infraestrutura de transporte e armazenamento, assim como fortes (como o de Cabo Frio) como forma de proteção ao território, especialmente contra corsários franceses.

Em seguida, o Ciclo da Cana, caracterizado pela monocultura de exportação, promoveu fluxos migratórios pelas áreas costeiras, adentrando, em certa

\footnotetext{
1 A ideia de ciclos é contestada por alguns historiadores, dado que estas fases econômicas não eram estanques, mas se sobrepunham em parte do tempo histórico. Aqui, no entanto, vamos manter essa nomenclatura, já que o objetivo é oferecer argumentos geográficos à análise territorial.
}

medida, nas capitanias hereditárias. Os canaviais requeriam extensas áreas para seu cultivo e este ciclo econômico expandiu a ocupação da colônia, tanto para áreas mais interiores como para mais ao sul (Capitania de São Vicente).

Em relação ao Ciclo do Ouro, a movimentação pelo território se dá de forma diferente, já que ela é maior na fase anterior ao seu descobrimento. E como no Brasil a descoberta do ouro se deu tardiamente (comparativamente com as colônias espanholas), sua busca gerou grande movimentação pelo território e foi responsável pela ocupação de terras longínquas da colônia, como a atual região Centro-oeste. Quando o ouro é encontrado, no entanto, há uma fixação da população no entorno das minas com a consequente criação de infraestrutura e de atividades para sua subsistência, gerando os ambientes mais urbanos da colônia portuguesa, nas Minas Gerais.

Com o Brasil já independente de Portugal, mas com a atual configuração territorial ainda não completada, ocorreram mais dois importantes ciclos econômicos. Com o Ciclo do Café (séculos XIX e XX) voltamos à biomassa e, à semelhança da cana-de-açúcar, caracterizava-se pela monocultura de exportação, mas com uma diferença: o café exigia climas mais amenos e, por isso mesmo, podia ser cultivado também em áreas serranas. A chamada "marcha do café" favoreceu mais uma vez o deslocamento da população e uma ocupação mais permanente do território (já que se trata de uma cultura perene) especialmente na região sudeste, adentrando em São Paulo pelo Vale do Paraíba, indo até o norte do Paraná.

No final do século XIX, o Ciclo da Borracha deslocou grandes contingentes do Nordeste para a Amazônia em busca desta nova riqueza. $O$ relativo povoamento da região norte foi suficiente para, numa disputa territorial, o Brasil incorporasse o Acre que pertencia à Bolívia, já que ali viviam mais brasileiros do que bolivianos.

As características destes ciclos econômicos e dos recursos naturais que os sustentaram convergem com a $1^{\underline{\underline{a}}}$ e $2^{\underline{a}}$ premissas aqui utilizadas, pelas quais $\mathrm{o}$ 
domínio territorial tem sua ocupação como pré-requisito, e que as biomassas promovem maior povoamento, fundamental para a integridade territorial.

América Espanhola $\rightarrow$ predomínio de recursos minerais

A história da América Espanhola, por sua vez, está em grande parte relacionada com recursos naturais de origem mineral, especialmente a prata e o ouro. A mineração é uma atividade econômica pontual e, portanto, concentradora de população, e não difusora de população como a biomassa. Isto porque os recursos minerais ocorrem em situações físicogeográficas específicas e é a concentração de determinados elementos que lhes atribui valor. Como consequência, as áreas mineradoras tendem a se urbanizar mais rapidamente, em oposição às áreas de cultivos que permanecem rurais por muito mais tempo, já que esta concentração populacional necessita de infraestrutura e muitos itens de subsistência. Isto poderia ajudar a explicar porque a América Espanhola é mais urbana que a América Portuguesa. Os ambientes urbanos seriam, pela própria concentração de população e de trocas de ideias, ambientes mais propícios aos movimentos revolucionários que foram muito mais efetivos na América Espanhola do que na Portuguesa. Lá, os movimentos revolucionários estiveram, em grande parte, relacionados às cidades que, por sua vez, estavam economicamente assentadas na atividade mineradora. Entre os principais "libertadores da América" figuram José de San Martin que liderou a independência da Argentina, do Chile e do Peru, além de Simon Bolívar que conduziu a independência de países como a Bolívia, Venezuela e Colômbia.

Estes argumentos sustentam a $3^{\text {a }}$ premissa, pela qual a mineração é concentradora de população, o que favorece a urbanização e, como decorrência, movimentos revolucionários.

Na colônia portuguesa, confirmando a relação entre mineração, ambiente-urbano e movimentos revolucionários que poderiam ter levado à independência de partes da colônia, aludimos à Inconfidência Mineira, ocorrida em ambiente urbano-minerador, mais progressista, pois entre sua população havia os mais cultos e críticos às condições impostas pela metrópole portuguesa à colônia.

Segunda variável: características físicas do território

América Portuguesa:

Do lado da América Portuguesa, o continente tem as seguintes características:

a) Relevo predominantemente planáltico, sendo que os planaltos sedimentares são bem mais extensos que os outros tipos de planaltos, como os orogênicos (serranos), por exemplo². Planaltos sedimentares, embora com altitudes médias em torno de 500m acima do nível do mar, apresentam superfícies aplanadas a colinosas, o que facilita muito tanto o deslocamento como o desenvolvimento de diversos tipos de atividades agrícolas e pecuárias.

b) Hidrografia densa e caudalosa, com destaque para as bacias amazônica, do Paraná e São Francisco, que tão importante foram na ocupação da colônia, já que em muitas regiões os rios constituíam-se das principais vias, o que ainda é uma verdade para o domínio amazônico. Mesmo em São Paulo, cujos rios são predominantemente planálticos, ou seja, menos navegáveis, eles tiveram grande importância na penetração do território (as monções). A Comissão Geográfica e Geológica de São Paulo, apesar dos obstáculos naturais, como corredeiras e cachoeiras, penetrava no interior do estado pelos rios para reconhecimento territorial, identificando os solos, o relevo e a própria hidrografia. Este conhecimento daria subsídio à expansão da cultura cafeeira no estado e a abertura de vias e ferrovias.

\footnotetext{
${ }^{2}$ De acordo com a classificação do relevo brasileiro de ROSS (2006), os planaltos dividem-se em: sedimentares (sobre bacias sedimentares que foram destacadas do entorno pela circundenudação), planaltos orogênicos (serras), planaltos arqueados cristalinos (como o sul riograndense e o planalto da Borborema) e os planaltos residuais, que se constituem em um conjunto de superfícies elevadas, como chapadas antigas, intrusões, inselbergs etc, a exemplo dos planaltos residuais sul e norte amazônicos.
} 


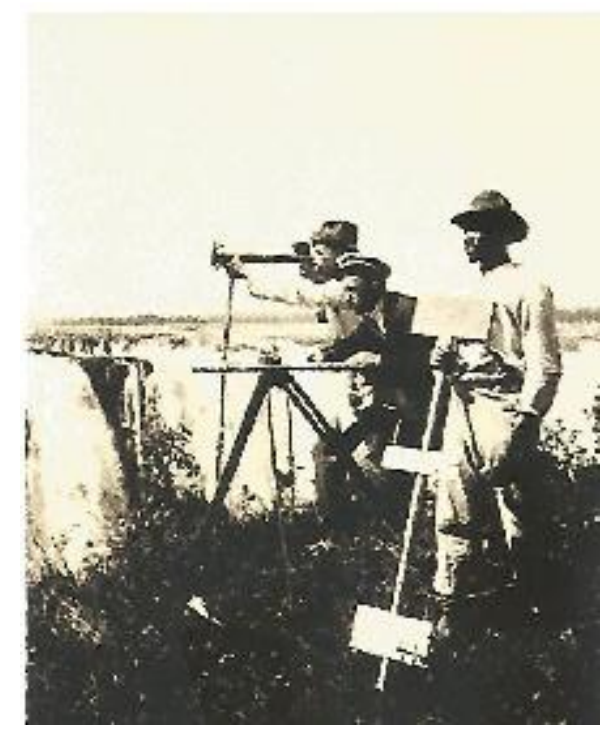

Figura 2 - Comissão Geográfica e Geológica de São Paulo fazendo reconhecimento do território, em Salto dos Patos, no rio Grande, na divisa entre Minas Gerais e São Paulo (1910). Fonte: VENTURI, 2010, p.16).

c) Diferentes climas que favorecem a ocorrência de diferentes domínios paisagísticos, além de diversas culturas. No domínio amazônico o clima equatorial criou um mosaico de biodiversidade que oferecia muitos produtos de interesse às metrópoles europeias, como as drogas do sertão, e mesmo o látex. Já no Nordeste, o clima tropical era propício ao cultivo da cana, espécie que necessita de um período de estiagem para se desenvolver melhor. No Sudeste, o clima tropical a subtropical favoreceu a expansão do café e, em áreas sedimentares, a pecuária. Além disso, a ausência de climas extremos tornava o território brasileiro totalmente ecúmeno.

Estas três características atendem, no seu conjunto, à $4^{a}$ premissa, que as relaciona com a facilidade de ocupação, deslocamento e desenvolvimento de atividades agropecuárias.

América Espanhola:

Do lado da América Espanhola, as principais características físico-territoriais são:

a) Relevos predominantemente montanhosos pela ocorrência da cordilheira dos Andes. Este fato, sobretudo naquela época, representava forte restrição a diversas atividades, sobretudo a agricultura de exportação e a pecuária. Além disso, as vertentes fortemente escarpadas também desfavorecem o deslocamento e a ocupação, se comparada aos terrenos sedimentares da colônia portuguesa.

b) Hidrografia menos densa e caudalosa, se comparada ao lado português. Com exceção da bacia do Paraná e Prata, que abrange os atuais Paraguai, Bolívia, Argentina e Uruguai, grande parte dos rios existentes são menos navegáveis, dado o alto gradiente fluvial ${ }^{3}$, a exemplo dos formadores do rio Solimões, no Peru.

c) Em relação ao clima, a América Espanhola, diferentemente da portuguesa, apresenta extremos climáticos, tanto no que se refere a baixas temperaturas no sul do continente ou nos topos e altiplanos andinos, como em relação à aridez, exemplo da costa do norte do Chile (deserto de Atacama) e do Peru.

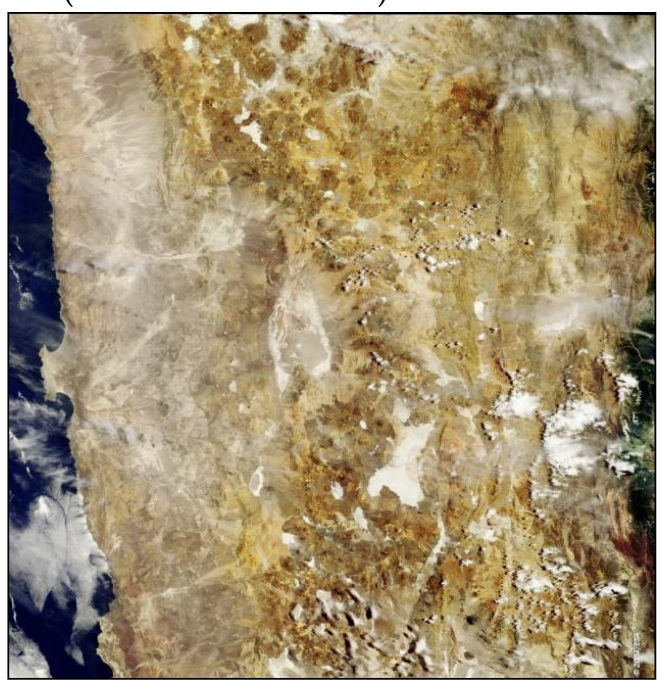

Figura 3 - Deserto de Atacama, visto de imagem de satélite.

Se as baixas temperaturas desfavoreciam cultivos de valor para as metrópoles, mais interessadas em produtos tropicais e exóticos, a aridez impossibilitava quaisquer outras atividades econômicas.

Estas três características atendem, no seu conjunto, à $4^{\mathrm{a}}$ premissa que as relaciona com maiores restrições de ocupação, deslocamento e desenvolvimento de atividades agropecuárias.

\footnotetext{
${ }^{3}$ Gradiente fluvial, em breve, refere-se à diminuição altimétrica no terreno para cada $\mathrm{km}$ de rio percorrido. No caso de relevo montanhoso, este gradiente é alto; no caso de relevo de planície, este gradiente é baixo, tornando, o rio mais navegável.
} 


\section{Discussão e Conclusão}

As duas variáveis analíticas associamse e se interferem mutuamente. Tanto as características físicas da colônia portuguesa, assim como os recursos disponíveis ou propícios ao cultivo favoreceram uma maior movimentação da população pelo território, sua ocupação e, consequentemente, a manutenção de sua integridade.

No lado espanhol, as restrições impostas pela cordilheira dos Andes, pelos climas extremos e pelo alto gradiente fluvial dos rios desfavoreciam as atividades relacionadas à agricultura e à pecuária, que permaneciam predominantemente como atividades de subsistência. Estas limitações foram, no entanto, compensadas pela mineração, atividade que teria gerado riquezas, favorecido a concentração da população nas áreas mineradoras e, consequentemente, o desenvolvimento de núcleos urbanos e movimentos revolucionários.
Concluímos então, que as variáveis geográficas (associadas e interdependentes) complementam-se e podem se associar àquelas variáveis históricas já consagradas para promover uma compreensão mais abrangente e completa sobre a configuração territorial do continente sul-americano: um grande país rodeado de países menores.

\section{Referências}

Donghi $\mathrm{T}$ H. História da América Latina. $4^{\text {th }}$ ed. Rio de Janeiro: Paz e Terra; 2005.

Donghi T H. Galeano E. As veias abertas da América Latina. Rio de Janeiro: Paz e Terra, 1971.

Ross J L S. editor. Geografia do Brasil. São Paulo: Edusp, 2006.

Venturi L A B. A riqueza de recursos do Brasil: pressupostos naturais. In: Recursos Naturais do Brasil. São Paulo: Editora Sarandi (prelo). 